\title{
Langerhans Cell Sarcoma
}

National Cancer Institute

\section{Source}

National Cancer Institute. Langerhans Cell Sarcoma. NCI Thesaurus. Code C6921.

A neoplastic proliferation of Langerhans cells with overtly malignant cytologic features. It can be considered a higher grade variant of Langerhans cell histiocytosis (LCH) and it can present de novo or progress from antecedent LCH. (WHO, 2001) 